\title{
La historicidad como límite Reseña bibliográfica de: Rufinetti, E. (2018). La racionalidad práctica en el debate Habermas-Gadamer. Villa Maria: Eduvim. 372 pp.
}

Palabras clave: Hermenéutica - Teoría Crítica - Ciencias Humanas - Filosofía Práctica

Keywords: Hermeneutics - Critical Theory - Humanities - Practical Philosophy

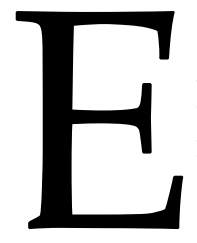

ste libro de Edgar Rufinetti, resultado de sus investigaciones doctorales, se propone abordar el debate entre Hans-Georg Gadamer y Jürgen Habermas iniciado en 1967, concentrándose en la cuestión de la racionalidad práctica. Consecuentemente, la introducción ofrece un breve relato de la rehabilitación de la filosofía práctica que tuvo lugar en la segunda mitad del siglo XX, que ayuda a contextualizar el ámbito político intelectual en el que se produjo el debate. Allí, Rufinetti explicita su objetivo de "elucidar los estándares de racionalidad que resultan 'adecuados' para orientar la acción y la reflexión en el ámbito de la praxis" (p.35). Con ese objetivo en mente, el debate que sirve de cuerpo a este trabajo se presenta dentro de un espectro más amplio de preocupaciones que se refieren a las condiciones en las que se produce la mediación que es objeto de las humanidades en general, dejando adivinar la conclusión a la que arribará, según la cual la razón práctica que viniera a disputar el lugar preponderante del positivismo en las ciencias sociales aparece siempre situada en el trasfondo del mundo de la vida, eludiendo cualquier intento de establecer un conjunto abstracto de referencias que permita el distanciamiento y la universalización de los presupuestos que orientan la tarea de la interpretación social.

A continuación, el libro, en efecto, se estructura como un diálogo, una dialéctica de pregunta y respuesta entre los dos autores, en donde se exponen alternadamente sus teorías. Con esto, Rufinetti logra mostrar la progresión en la argumentación de ambos contendientes, para lo cual recurre tanto a textos efectivamente producidos en función de la disputa como a otros trabajos que complementan y amplían las perspectivas que la contienen.

Rufinetti muestra el esfuerzo de Habermas por escapar a la conclusión -tal vez la única conclusión normativa- de la hermenéutica filosófica de Gadamer, a saber, que la comprensión en todas sus formas se encuentra siempre limitada $\mathrm{y}$, en ese sentido, posibilitada por la tradición lingüísticamente mediada en la que se enmarca. Esto es así 
debido al argumento ontológico que preside la filosofía hermenéutica, según el cual el sujeto y el objeto de la comprensión no preceden, sino que se constituyen mediante el acto de la comprensión. Este axioma, que va al encuentro de la premisa de distanciamiento que es condición de posibilidad de la teoría crítica, se presenta como una especie de planaridad, en el sentido pictórico del término, que pone de manifiesto la imposibilidad de separar fehacientemente a las interpretaciones de los hechos, a la autoridad de la verdad, al significado de la validez y también al sujeto del objeto, que es siempre la tradición propia. Y esta es sin duda una conclusión inquietante.

Por el contrario, Habermas entiende que comprender se refiere a la posibilidad de "ir por detrás" del lenguaje, para encontrar el plano en el que se explicitan sus fundamentos y estructuras originales, no distorsionadas. Desaprovecha, en ese sentido, la propuesta de entender la relación entre lo universal y lo particular -o entre teoría y práctica- en términos de "fiesta" como propusiera Gadamer, es decir, se resiste a reconocer la artificialidad de la distinción entre lenguaje y poder o entre lenguaje y violencia. Como consecuencia, continúa empleando una concepción instrumental de la hermenéutica, más cercana a su versión romántica, que es entonces "aplicada" como una herramienta disponible para la crítica de la ideología, rechazando la incertidumbre o el pesimismo, que, desde la perspectiva de una teoría con objetivos emancipatorios idealistas, es intrínseco al planteo ontológico gadameriano.

En consonancia con lo que podríamos llamar su idealismo o su romanticismo, la estrategia de Habermas descansa ella misma sobre la autoridad que se atribuye al intérprete culto, sea en carácter de terapeuta o de reconstructor (p. 313), como sujeto capaz de poner de manifiesto las estructuras sobre las cuales se asienta cualquier elocución o cualquier discurso. Y si bien podemos compartir el interés emancipatorio del fundamento crítico de la teoría de la competencia comunicativa de Habermas en tanto que objetivo político o deseo, esto es, el objetivo de conformar una "comunidad intersubjetiva de la comprensión mutua, del saber compartido, de la confianza recíproca y de la concordancia de unos con otros" (citado en la p. 273), el objetivo de conformar una comunidad transparente en la que cada uno pudiera participar de manera consciente, voluntaria y racional continúa basándose en una presuposición que, aunque se supone normativa, no deja de ser un deseo. Esto es, Habermas presupone la existencia objetiva de un sistema de referencias formal y universal que conforma una normalidad en el sentido clínico del término, que puede desagregarse de actitudes patológicas que la envuelven, ocultan, falsean o contaminan. Y eso es un problema, porque presupone asimismo la capacidad de los participantes (por lo menos de los participantes cultos) de la interacción para identificar y desenmascarar las pretensiones de validez que operan en cualquier acto de habla, o sea, la competencia para visualizar la violencia estructural inscripta en toda relación comunicativa. En otras palabras, presupone un sujeto previamente constituido que, munido de la instrucción adecuada, es capaz de ejercer el distanciamiento y autorreflexión que permiten el abordaje crítico de un objeto ya inscripto en el sistema formal de referencias expuesto. Rufinetti ayuda a reconocer el 
problema de estas presuposiciones incluso para la teoría crítica: si Gadamer tiene razón, $\mathrm{y}$ estas distinciones no son asequibles, entonces acabaremos reproduciendo y solidificando la violencia estructural que se pretende poner a descubierto.

El resultado de la rehabilitación de la razón práctica operado por Gadamer es, para Rufinetti, un desplazamiento de "la problemática de la racionalidad de la relación sujetoobjeto a la relación particular-general" (p. 332), lo cual afecta directamente al paradigma científico de las ciencias sociales como las conocemos hoy en día, pues escapa a las categorías trascendentales y habita en el lenguaje hablado, en el diálogo constituido entre partícipes interesados. El diálogo presupone, en definitiva, un estado de abierto, un cuestionamiento de las propias valoraciones (o prejuicios) respecto de lo que sea bueno y justo, de modo que la pretensión de verdad del interlocutor pueda realmente ser considerada como una posibilidad, y la consciencia de la propia finitud, es decir, de que nuestros juicios son provisionales no porque el futuro garantice un juicio siempre mejorado, sino porque cualquier comprensión estará siempre limitada por nuestro horizonte particular.

Tal modalidad de la provisionalidad, en la que nos vemos obligados a revisar nuestros prejuicios una y otra vez en función de los efectos que el desarrollo del diálogo tiene sobre su consecución es, justamente, el carácter de la razón práctica defendida por Gadamer, que Habermas se resiste a aceptar, apelando a la lingüística o al psicoanálisis en busca de una pragmática universal capaz de escapar a la espiral de la historicidad.

Rufinetti muestra en su capítulo final que, en sus esfuerzos por montar una estructura que garantice la distinción entre acuerdos reales y acuerdos falsos, capaz de servir como base universal de la interpretación social incorporando al mundo de la vida como un saber contextual y aproblemático, Habermas acaba por erosionar su propia empresa de una teoría pragmática universal. Ninguna clasificación será suficiente para incorporar la complejidad del mundo de la vida en el análisis crítico de la realidad social, aun si fuera cierto que la diversificación de sistemas que fragmentan política o analíticamente el mundo de la vida constituye segmentos efectivamente discretos de acción capaces de "colonizar" un mundo de la vida también autónomo u objetivable.

Finalmente, vale la pena prestar atención a la problematización que Rufinetti propone sobre el tema de la mediación. Esto es, sobre el problema de qué es mediado, dónde, por parte de quién y a través de qué modalidad. El problema de la mediación de sentido se convierte en un subtexto del libro y proporciona un substrato que guía la interpretación que Rufinetti moviliza sobre la racionalidad práctica. En efecto, para el autor la descripción de la mediación que tiene lugar en la interpretación social es lo que diferencia las posturas de Gadamer y Habermas, definiendo en última instancia en qué consiste una racionalidad práctica que ambos autores reconocen como propia. Si para Habermas ésta designa la decisión libremente ejecutada del sujeto de encontrarse críticamente con el pasado o el presente estructuralmente violento que lo define, para Gadamer este concepto sirve para describir la indistinción entre conocimiento teórico y aplicación que lo constituye en sujeto de la tradición, igualmente partícipe de la 
violencia. La imposibilidad de escapar completamente a las determinaciones contextuales que la hermenéutica gadameriana reconoce moviliza la búsqueda de un ancla racional que garantice la certeza de distinguir la justicia de la deformación que, para Rufinetti, Habermas no logra (tristemente) alcanzar.

Eugenia Gay

Universidad Nacional de Córdoba eugeniagay@gmail.com

Para citar esta reseña:

Gay, Eugenia (2020): La historicidad como límite. Reseña bibliográfica de: “Rufinetti, E. (2018). La racionalidad práctica en el debate Habermas-Gadamer. Villa Maria: Eduvim. 372 pp." Anuario de la Escuela de Historia Virtual, 17, 150-153. 